\title{
PENGARUH KEBIJAKAN DIVIDEN DAN DAN PERTUMBUHAN PERUSAHAAN TERHADAP NILAI PERUSAHAAN DI BEI
}

\author{
Rina Yuniarti \\ Dosen Fakultas Ekonomi Universitas Muhammadiyah Bengkulu
}

\begin{abstract}
ABSTRAK
Rina Yuniarti; Penelitian ini bertujuan untuk mengetahui pengaruh kebijakan dividen, pertumbuhan perusahaan terhadap nilai perusahaan. The populationin ini studyis manufaktur companylisted dari Bursa Efek Indonesia (BEI) pada tahun dari tahun 2006 sampai 2010.The hipotesis dari penelitian ini diuji dengan exploning beberapa regresi dan nalysis regresi teknis SPSS 18. Penelitian ini faund bahwa kebijakan dividen dan pertumbuhan perusahaan nilai perusahaan infemence positif.
\end{abstract}

\section{ABSTRACT}

Rina Yuniarti; This study aimed to determine the effect of dividend policy, the company's growth to firms value. The populationin this study is the manufacturing company listed of the Indonesia Stock Exchange (BEI) in the year from 2006 to 2010.The hipotesis of this study were tested by exploring multiple regresi and technical regression nalysis SPSS 18. This study faund that dividen policy and company's growth positive infemence firm value.

Key words: dividend policy, the company's growth and firm value

\section{PENDAHULUAN}

Nilai suatu perusahaan sangat dipengaruhi oleh keputusan pemilihan sumber dana baik yang berasal dari dalam maupun dari luar perusahaan. Sumber dana perusahaan dari internal berasal dari laba ditahan dan depresiasi. Sumber dana eksternal perusahaan berasal dari kreditur. Pemenuhan kebutuhan dana yang berasal dari para kreditur merupakan hutang bagi perusahaan. Sedangkan dana yang diperoleh dari para pemilik merupakan modal sendiri. Keputusan pendanaan keuangan perusahaan juga akan sangat menentukan kemampuan perusahaan dalam melakukan aktivitas operasinya (Safrida, 2008)

Nilai perusahaan dapat di artikan sebagai ekspetasi nilai investasi pemegang saham (harga pasar ekuitas) dan/atau ekspektasi nilai total perusahaan, harga pasar ekuitas ditambah dengan nilai pasar hutang, atau ekspektasi harga pasar aktiva (Sugihen, 2003). Machfoedz, (1996) pertumbuhan (growth) adalah seberapa jauh perusahaan menempatkan diri dalam sistem ekonomi secara keseluruhan atau sistem ekonomi untuk industri yang sama.

Investor yang menanamkan modalnya pada suatu perusahaan mengharapkan return atau keuntungan yang akan diperolehnya dari investasi yang telah dilakukanya. Keuntungan dari penanaman modal melalui pembelian saham suatu perusahaan terdiri dari dua macam, yaitu berupa dividen dan capital gain.Dividen merupakan bagian keuntungan yang diberikan kepada investor berdasarkan laba operasi yang diperoleh perusahaan dan kebijakan dividen yang ditetapkan oleh perusahaan. Kebijakan dividen merupakan suatu kebijakan yang ditetapkan oleh perusahaan untuk menetapkan berapa bagian dari laba bersih yang akan dibagikan sebagai dividen kepada para pemegang saham dan berupa bagian dari laba bersih itu akan ditanamkan kembali sebagai laba yang di tahan untuk reinvestasi. Sedangkan capital gain adalah keuntungan yang diperoleh investor karena adanya selisih harga jual saham yang lebih tinggi diharga beli apabila saham tersebut dijual (Sartono, 2001).

Pertumbuhan (Growth) adalah seberapa jauh perusahaan menempatkan diri dalam sistem ekonomi secara keseluruhan atau sistem ekonomi untuk industri yang sama. Pada umumnya, perusahaan yang tumbuh dengan cepat memperoleh hasil positif. Pertumbuhan cepat juga memaksa sumber daya manusia yang dimiliki untuk secara optimal memberikan kontribusinya. 
Berdasarkan uraian yang telah dijelaskan diatas, maka penulis tertarik untuk melakukan penelitian dengan judul " Pengaruh Kebijakan Dividen Dan dan Pertumbuhan Perusahaan Terhadap Nilai Perusahaan Di BEI”.

\section{Landasan Teori \\ Kebijakan Dividen}

Kebijakan dividen merupakan keputusan pembayaran dividen yang mempertimbangkan maksimalisasi harga saham saai ini dan periode mendatang. Dalam penentuan besar kecilnya dividen yang akan dibayarkan kepada perusahaan yang sudah merencanakan dengan menetapkan target Dividend Payout Ratio didasarkan atas perhitungan keuntungan yang diperoleh setelah dikurangi pajak. Untuk dapat membayar dividen dapat dibuat suatu rencana pembayaran. Brigham (1999) menjelaskan bahwa:

1. Perusahaan mempunyai target Dividend Payuot Ratio jangka panjang

2. Manajer memfokuskan pada tingkat pertumbuhan dividen dari pada tingkat absolute.

3. Perubahan dividen yang meningkat dalam jangka panjang, untuk menjaga penghasilan.

4. Manajer bebas membuat perubahan dividen untuk keperluan cadangan.

Penentuan besarnya dividen payout ratioakan menentukan besar kecilnya laba yang ditahan. Setiap ada penambahan laba yang ditahan berarti ada penambahan modal sendiri dalam perusahaan yang diperoleh dengan biaya murah.

Rozeff (1982) dan Easterbook (1984) menyatakan bahwa pembayaran dividen kepada pemegang saham akan mengurangi sumber-sumber dana yang dikendalikan oleh manajemen. Semakin tinggi dividen yang dibayarkan kepada pemegang saham maka free cash flow dalam perusahaan makin kecil. Hal ini mengakibatkan manajemen harus memikirkan untuk memperoleh sumber dana dari luar yang bias saja berupa hutang. Dengan demikian, semakin tinggi dividen yang dibayarkan maka kemungkinan perusahaan melakukan kebijakan hutang akan semakin tinggi.

\section{Pertumbuhan Perusahaan}

Perusahaan dengan tingkat pertumbuhan yang tinggi, dalam hubunganya dengan leverage, sebaiknya menggunakan ekuitas sebagai sumber pembiayaanya agar tidak terjadi biaya keagenan antara pemegang saham dengan manajemen perusahaan, sebaliknya perusahaan dengan tingkat pertumbuhan yang rendah sebaiknya menggunakan hutang sebagai sumber pembiayaanya karena penggunaan hutang akan mengharuskan perusahaan tersebut membayar bunga secara teratur. Semakin besar kebutuhan untuk pembiayaan mendatang maka semakin besar keinginan perusahaan untuk menahan laba. Jadi perusahaan yang sedang tumbuh sebaiknya tidak membagikan laba sebagai dividen tetapi lebih baik digunakan untuk ekspansi. Sartono (2001) menyatakan semakin besar biaya riset and development-nya maka berarti ada prospek perusahaan untuk tumbuh.

\section{Hipotesis}

\section{$H_{1}$ : Kebijakan dividen berpengaruh positif terhadap nilai perusahaan $\mathrm{H}_{2}$ :Pertumbuhan perusahaan berpengaruh positif terhadap nilai perusahaan}

\section{HASIL DAN PEMBAHASAN Sampel Penelitian}

Populasi dalam penelitian ini adalah perusahaan-perusahaan manufaktur yang terdaftar di BEI (Bursa Efek Indonesia) periode tahun 2006 sampai dengan tahun 2010. Penentuan sampel diperoleh 70 perusahaan yang menjadi sampel. Teknik pengambilan sampel yang digunakan adalah random sampling. 


\section{Deskriptif Statistik Variabel Penelitian}

Deskriptif statistik memberikan gambaran umum tentang objek penelitian yang dijadikan sampel. Penjelasan data melalui deskriptif statistik diharapkan dapat memberikan gambaran awal tentang masalah yang teliti. Deskriptif statistik difokuskan kepada nilai maksimum, minimum, rata-rata dan standar deviasi.

\section{Uji Normalitas}

Uji normalitas data dilakukan dengan cara uji statistik non-parametrik Kolmogorov smirnov (uji K-S).

Table 1. Uji statistik Kolmogorov-Smirnov

\begin{tabular}{|ll|l|l|l|}
\hline \multicolumn{2}{|c|}{ PTA } & \multicolumn{1}{l|}{ DPR } & MBR \\
\hline $\mathrm{N}$ & & 350 & 350 & 350 \\
Normal & Mean & .241317 & .309430 & $2.284931 \mathrm{E} 0$ \\
Parametersa & Std. & $1.2545270 \mathrm{E} 0$ & .8299957 & $3.6221181 \mathrm{E} 0$ \\
& Deviation & & .343 & .276 \\
Most & Absolute & .380 & .261 & .233 \\
Extreme & Positive & .378 & -.343 & -.276 \\
Differences & Negative & -.380 & 6.421 & 5.164 \\
Kolmogorov-Smirnov Z & 7.118 & .000 & .000 \\
Asymp. Sig. (2-tailed) & .000 & &
\end{tabular}

a. Test distribution is

Normal.

\section{Uji Autokorelasi}

Uji autokorelasi bertujuan untuk menguji apakah dalam model regresi linear ada korelasi antara kesalahan pengganggu periode sekarang dengan periode sebelumnya.Autokorelasi muncul karena observasi berurutan sepanjang waktu yang berkaitan satu dengan yang lainya.Uji autokorelasi pada penelitian ini menggunakan uji Durbin-Watson (DW test).

Dengan menggunakan pendekatan tersebut, maka DW adalah sebesar 1,979 sehingga sesuai dengan keputusan DW maka dapat ditarik kesimpulan bahwa terjadi autokorelasi.Dan dapat dilihat pada 4.4 sebagai berikut:

\section{Tabel 2. Uji Autokorelasi}

\begin{tabular}{|c|c|c|c|c|c|}
\hline \multicolumn{6}{|c|}{ Model Summaryb } \\
\hline Model & $\mathrm{R}$ & R Square & $\begin{array}{l}\text { Adjusted R } \\
\text { Square }\end{array}$ & $\begin{array}{l}\text { Std. Error of } \\
\text { the Estimate }\end{array}$ & $\begin{array}{l}\text { Durbin- } \\
\text { Watson }\end{array}$ \\
\hline 1 & $.288^{\mathrm{a}}$ & .083 & .075 & 2.93362 & 1.979 \\
\hline
\end{tabular}

a. Predictors: (Constant), NPTA, NDER

b. Dependent Variable: NMBR

\section{Uji Multikolinearitas}

Uji multikolenearitas bertujuan untuk menguji apakah ada korelasi antar variabel bebas (independen). Model regresi yang baik adalah apabila tidak ada korelasi antara variabel independen karena jika terjadi korelasi maka variabel-variabel menjadi tidak orthogonal yang 
berarti variabel independen sama dengan nol. Untuk melihat nilai multikolenearitas dalam penelitian ini menggunakan nilai tolerancedan variance inflanation factor (VIF). Nilai tolerance rendah sama dengan nilai VIF yang tinggi karena VIF $=1 /$ tolerance. Nilai cut off yang dipakai umum untuk menunjukkan ada tidaknya multikolenearitas adalah nilai tolerance $<0,10$ atau sama dengan VIF > 10. Adapun hasil pengujian multikolinieritas dapat dilihat pada Tabel 4.5 berikut ini:

\section{Tabel 3. Uji Multikolinearitas}

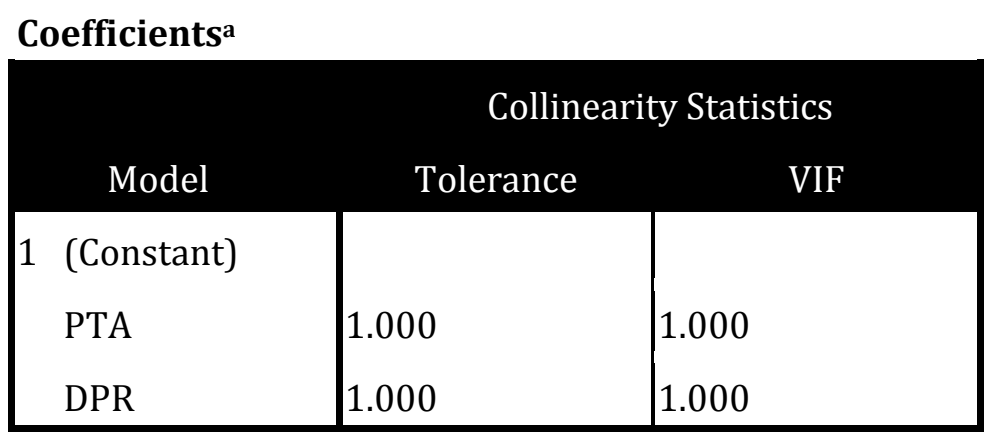

\section{Uji Heteroskedastisitas}

Jika nilai variabel independen signifikan yang berarti mempengaruhi variabel dependen maka dapat disimpulkan ada indikasi bahwa telah terjadi heterokedastisitas. Hasil dari pengujian heterokedastisitas dapat dilihat dalam tabel 4.6 sebagai berikut:

Tabel 4. Hasil Uji Heteroskedastisitas

\begin{tabular}{|l|r|r|r|}
\hline Variabel & Koefisien & \multicolumn{1}{|c|}{ Tig } \\
\hline (Constant) & 1.574 & 5.907 & .000 \\
PTA & -.049 & -.324 & .746 \\
DPR & .534 & 2.330 & .020 \\
\hline
\end{tabular}

Sumber: Data sekunder diolah tahun 2012

\section{Pengujian Goodness of Fit Model}

Nilai $\mathrm{R}$ square $\left(\mathrm{R}^{2}\right)$ atau nilai koefisien determinasi digunakan untuk mengukur seberapa besar kemampuan model dalam menerangkan variasi variabel dependen.Nilai $\mathrm{R}^{2}$ adalah diantara nol dan satu.Nilai $\mathrm{R}^{2}$ yang kecil berarti kemampuan variabel independen dalam menjelaskan variasi variabel dependen sangat terbatas.Nilai yang mendekati satu berarti variabel independen memberikan hampir semua informasi yang dibutuhkan untuk memprediksi variasi variabel dependen. Nilai $\mathrm{R}^{2}$ sebesar 0,046 mempunyai arti bahwa variabel dependen mampu dijelaskan oleh variabel independen sebesar 4,6\%. Dengan kata lain 4,6\% nilai perusahaan mampu dijelaskan variabel struktur modal, kebijakan dividen dan pertumbuhan perusahaan, sedangkan 95,4\% dijelaskan oleh faktor lain yang tidak diikutkan dalam penelitian ini.

Tabel 5. Nilai R Square

\begin{tabular}{|l|r|r|r|r|}
\hline Model & \multicolumn{1}{c}{$\mathrm{R}$} & R Square & $\begin{array}{c}\text { Adjusted R } \\
\text { Square }\end{array}$ & $\begin{array}{r}\text { Std. Error of } \\
\text { the Estimate }\end{array}$ \\
\hline 1 & $.213^{\mathrm{a}}$ & .046 & .037 & 3.5539257 \\
\hline
\end{tabular}

a. Predictors: (Constant), DPR, PTA, 


\section{Pengujian Hipotesis dan Pembahasan}

Pengujian hipotesis 1 dan 2 dilakukan dengan menggunakan analisis regresi linear berganda. Hasil pengujian hipotesis 1 dan 2 dapat digambarkan pada tabel 6. berikut:

Tabel 6. Hasil Pengujian Hipotesis

\begin{tabular}{|l|l|l|}
\hline Variabel & \multicolumn{1}{l}{ Coefficients } & \multicolumn{1}{l|}{ T test } \\
\hline Constant & 1.574 & $5.907^{* * *}$ \\
\hline DPR & 0.534 & $0.020^{* *}$ \\
\hline PTA & -0.049 & -0.324 \\
\hline F Test & 5.507 & \\
\hline Sig & $001^{* * *}$ & \\
\hline $\mathrm{R}^{2}$ & .046 & \\
\hline
\end{tabular}

Keterangan:

$* * *=$ Signifikan $1 \%$

** $=$ Signifikan $5 \%$

\section{Pengujian Hipotesis Pertama}

Hipotesis kedua dalam penelitian ini adalah untuk membuktikan bahwa kebijakan dividen berpengaruh positif terhadap nilai perusahaan. Berdasarkan hasil pengujian statistik, dapat dilihat nilai koefisien regresi dari variabel kebijakan dividen (DPR) adalah sebesar 0,534 dengan tingkat signifikansi sebesar 0,020. Hal ini menunjukkan bahwa kebijakan dividen berpengaruh positif dan signifikan terhadap nilai perusahaan dengan tingkat signifikansi lebih kecil dari $0.05(\alpha)$.Dari hasil uji statistik yang telah dilakukan membuktikan bahwa variabel kebijakan dividen berpengaruh positif terhadap nilai perusahaan, maka dalam hal ini hipotesis dua $\left(\mathrm{H}_{2}\right)$ dalam penelitian ini diterima.

Dari hasil penelitian ini menemukan bukti empiris bahwa kebijakan dividen berpengaruh secara langsung dan positif terhadap nilai perusahaan yang terjadi antara tahun 2006 sampai dengan tahun 2010.

\section{Pengujian Hipotesis Kedua}

Hasil penelitian ini menunjukkan bahwa pertumbuhan perusahaan berpengaruh negatif namun tidak signifikan terhadap nilai perusahaan. Hal ini dapat dilihat dari hasil uji statistik yang menunjukkan nilai koefisien regresi pertumbuhan perusahaan (PTA) sebesar -0,049 dan $\rho$-value 0,746. Dari nilai koefisien regresi dapat disimpulkan bahwa setiap ada penurunan pertumbuhan perusahaan sebesar 1 satuan maka akan berpengaruh pada peningkatan nilai perusahaan sebesar 0,049 satuan.Hasil temuan ini terbukti menolak hipotesis 2 (H2) yang mengatakan bahwa pertumbuhan perusahaan berpengaruh positif terhadap nilai perusahaan dan sekaligus menjawab perumusan masalah ketiga dalam penelitian ini.

Hasil penelitian ini tidak konsisten dengan penelitian yang dilakukan oleh Sriwardany (2006) yang menemukan bahwa pertumbuhan perusahaan mempunyai pengaruh langsung dan positif terhadap perubahan harga saham pada perusahaan manufaktur yang terdaftar di BEI periode tahun 2000 sampai dengan tahun 2004 dengan sampel 156 perusahaan. Ketidak konsistenan hasil penelitian ini diduga dipengaruhi oleh ukuran penentu pertumbuhan perusahaan, dimana penelitian terdahulu mengukur pertumbuhan perusahaan sebagai variabel independen dengan rasio Tobins'q dan perubahan harga saham sebagai variabel dependen. Penelitian ini menggunakan akar kuadrat dari perubahan total aktiva sebagai pertumbuhan perusahaan dengan periode tahun 2006 sampai dengan tahun 2010.

\section{Kesimpulan}


1. Kebijakan dividen berpengaruh positif terhadap nilai perusahaan pada perusahaan manufaktur yang listing di Bursa Efek Indonesia.

2. Pertumbuhan perusahaan berpengaruh positif terhadap nilai perusahaan pada perusahaan manufaktur yang listing di Bursa Efek Indonesia.

\section{Saran}

1. Untuk penelitian lanjutan disarankan untuk menggunakan sampel dari seluruh jenis perusahaan yang terdaftar di Bursa Efek Indonesia.

2. Disarankan untuk penelitian selanjutnya untuk mempertimbangkan periode penelitian agar mendapatkan hasil yang lebih digeneralisir

\section{DAFTAR PUSTAKA}

Brigham, E.F., dan J. Houston. 2001. Manajemen Keuangan. Penerjemahan Hermawan Wibisono. EdisiKedelapan. Edisi Indonesia.Buku II. Jakarta: Erlangga.

Brigham, E.F., and L.C. gapenski. 1988. Financial Management Theory and Practice. Fith Edition.United State Of America.

Easterbrook, F. 1984. Two Agency-Cost Explanation of Dividen.American Economic Review.Vol 16.

Fama, E.F., danK.R.French. 1998. "Taxes, Financing Decision, and Firm Value". The Journal Of Finance; Vol. LIII. No.3, June, PP.819-843.

Ghozali, Imam. 2005. AplikasiAnalisis Multivariate Dengan Program SPSS.EdisiSatu. BadanPenerbitUniversitasDiponegoro, Semarang.

Gull, F.A and Jaggi B. 1999. An Analysis of Joint Effects of Investment Opportunity Set, Free Cash Flow And Size on Corporate Debt Policy. Review of Quantitative and Accounting 12, 371-381

Hasnawati, Sri. 2005. "Implikasi Keputusan nvestasi, Pendanaan dan Dividen terhadap Nilai Perusahaan Perusahaan Publik Di Bursa Efek Jakarta". Usahawan: No.09/Th XXXIX, Sepember 2005.

Helfert, E.A. 1997. TeknikAnalisisKeuangan. Penerjemah Herman Wibowo, EdisiKedelapan. Jakarta: Erlangga.

Jensen, M.C. 2001. "Value Maximization, Stakeholders Theory, and The Corporate Objective Function". Working Paper; No.01-09.Harvard Business School, PP.1-21. Or www.google.com/search

Kallapur, S., dan M.A. Trombley. 1999. "The Association Between Investment Opportunity Set Proxies and Realized Growth". Journal Of Business \& Accounting. 26 April/May. Pp.505519. or www.google.com/search

Keown J. Arthur, Scott Jr, David F, Petti William. 2000. Dasar-DasarManajemenKeuangan. Buku II. EdisiPertama. SalembaEmpat. Jakarta

Rozeff, M.S. 1982. Growth, Beta and Agency Cost as Determinants of Dividen Payout Ratios, Journal of Financial Research.

Safrida.2008. PengaruhStruktur Modal danPertumbuhan Perusahaan terhadapNilai Perusahaan di BEJ.TesisPascaSarjanaUniversitas Sumatera Utara. Medan. 
Sekaran, Uma. 2003. Research Methods For Business. Wiley.

Santoso, Singgih. 2006. MenguasaiStatistik Di Era InformasiDengan SPSS 15. Jakarta: Elex Media Komputindo.

Shin, H.H., dan R.M. Stulz. 2002. "Firm Value, Risk and Growth Opportunities". Banking and Monetory Economics at The Ohio State University, and Reseach, Hal. 1-35. Orwww.google.com/search 